\title{
Glyphosate and glufosinate-ammonium runoff from a corn-growing area in Italy
}

\author{
Claudio SCREPANTI, Cesare ACCINELLI*, Alberto VICARI, Pietro CATIZONE
}

Department of Agro-Environmental Science and Technology, University of Bologna, Viale Fanin 44, 40127 Bologna, Italy

(Accepted 4 May 2005)

\begin{abstract}
The main objective of this experiment was to estimate field-scale runoff losses of glyphosate and glufosinate-ammonium under natural rainfall conditions. Investigations were carried out at the Runoff Monitoring Station of the University of Bologna (Italy). Glyphosate and glufosinate-ammonium were applied as pre-emergence herbicides on $350-\mathrm{m}^{2}$ field plots characterized by a uniform slope of $15 \%$. Field plots were cultivated with corn. The persistence and sorption isotherms of the two herbicides were also determined. During the 3-year experimental period low runoff volumes were observed. More specifically, annual runoff volumes did not exceed $4.7 \mathrm{~mm}$. Glyphosate and glufosinate-ammonium concentrations in collected runoff samples rapidly declined with time. The highest glyphosate and glufosinateammonium concentrations were 16 and $24 \mu \mathrm{g} \mathrm{L}{ }^{-1}$, respectively. These peaks were observed in a runoff event occurring 1 day after herbicide treatment. The total maximum amount of glyphosate and glufosinate-ammonium losses were 0.031 and $0.064 \%$ of the applied active ingredients, respectively. On the basis of the obtained results, both glyphosate and glufosinate-ammonium showed low potential to contaminate surface water resources. These results were supported by their estimated short persistence and strong sorption in soil. The half-lives of glyphosate and glufosinate-ammonium were 17.5 and 6.4 days, respectively, and their distribution coefficients $\left(\mathrm{K}_{\mathrm{d}}\right)$ were 746.6 and $23.4 \mathrm{~mL} \mathrm{~g}^{-1}$, respectively.
\end{abstract}

glyphosate / glufosinate-ammonium / runoff / persistence / sorption

\section{INTRODUCTION}

Surface runoff can transport pesticides to surface water bodies including rivers, lakes and streams (Leonard, 1989; Burgoa and Wauchope, 1995; de Jonge et al., 2000). Runoff has been shown to be a major non-point source of pesticides to surface waters (Parr et al., 1998). Water quality data show that herbicides are the most frequently detected group of pesticides in surface water resources (Carter, 2000).

Factors that control runoff losses of herbicides from fields are slope of the fields, intensity and timing of rainfall after treatments, physico-chemical properties of herbicides and vegetative cover (Wauchope, 1978). According to some authors, the greatest herbicide runoff losses occur when excess rain is received soon after their application (Wauchope, 1978; Gaynor et al., 2001). Under average conditions, herbicide loss by water runoff is typically $<0.1$ to $1 \%$ of the applied active ingredient. Under certain localized circumstances, herbicide losses of up to $5 \%$ or greater were reported (Carter, 2000).

Glyphosate [ $N$-(phosphonomethyl)glycine] and glufosinate-ammonium [the ammonium salt of DL-homoalanin-4-yl(methyl)phosphinic acid] are broad-spectrum and extensively used herbicides. The use of these two herbicides has increased during recent years due to increased cultivation of herbicide- tolerant crops, mainly represented by glyphosate- and glufosinate-ammonium-tolerant crops (Shaner, 2000).

In soil, glyphosate and glufosinate-ammonium are readily degraded by microorganisms, with estimated half-lives ranging from 7 to 60 days and from 1 to 25 days, respectively (Gallina and Stephenson, 1992; Giesy et al., 2000; Accinelli et al., 2004). Both herbicides are strongly sorbed on soil mainly through their phosphonic acid moiety (Torstensson, 1985; Zaranyika and Nyandoro, 1993). Thus, based on persistence and sorption properties, these two herbicides are generally regarded as having low potential to contaminate surface water resources. Despite their wide use, most of the available literature dealing with the environmental fate of glyphosate and glufosinate-ammonium is based on laboratory investigations and only a few field-scale investigations have been conducted.

In a 3-year field study conducted in Ohio, Edwards et al. (1980) reported runoff losses of glyphosate ranging from $<0.01 \%$ to $1.85 \%$. The highest glyphosate losses were observed shortly after herbicide application, coinciding with high intensity runoff phenomena. Under such conditions, glyphosate concentrations in runoff water of up to $5 \mathrm{mg} \mathrm{L}^{-1}$ were reported. Similar herbicide runoff patterns were reported by Shipitalo and Malone (2000). In this latter investigation,

* Corresponding author: accinel@agrsci.unibo.it 


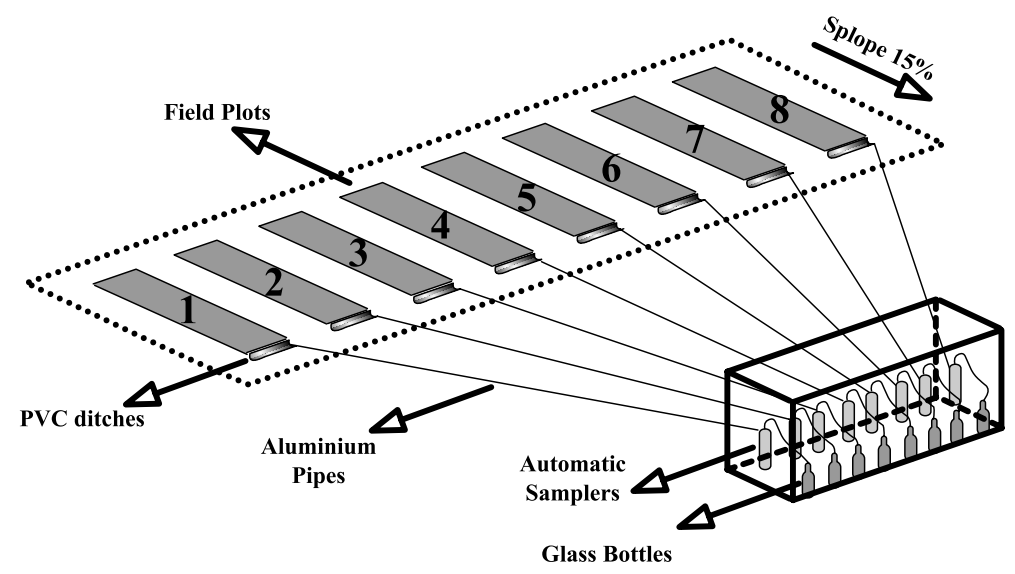

Figure 1. General layout of the experimental site (not drawn to scale). estimated losses did not exceed 0.2 and $0.08 \%$ of the applied glyphosate and glufosinate-ammonium, respectively.

The above described investigations were conducted under agro-environmental conditions considerably different from those of the Mediterranean area. Consequently, these data are not correctly transferable to agricultural systems of Southern Europe. In the agricultural areas of Southern Europe and more specifically of the Po Valley (Italy), the crop-growing period (from the beginning of spring to the beginning of winter) is characterized by a low number of high intensity rainfall events. This general rainfall trend is supposed to increase water and soil runoff risk in slope fields (Ventura et al., 2002).

Since 1990, several field investigations on herbicide runoff losses have been conducted at the Runoff Monitoring Station of the University of Bologna (Italy) (Rossi Pisa et al., 1999; Vicari et al., 1999). Investigations have included the estimation of runoff losses of a wide range of herbicides (i.e. atrazine, terbuthylazine, metolachlor, prosulfuron and triasulfuron) under different agricultural practices (i.e. conservative vs. conventional tillage). Under some circumstances, herbicide concentrations in runoff samples of up to $400 \mu \mathrm{g} \mathrm{\textrm {L } ^ { - 1 }}$ were observed (Vicari et al., 1999).

Considering the importance of glyphosate and glufosinateammonium in Italian agriculture, and throughout Southern Europe, the objective of the present study was to estimate runoff losses of glyphosate and glufosinate-ammonium from $350-\mathrm{m}^{2}$ field plots in a typical hilly area of Italy. Estimations of herbicide persistence and sorption in soil were also included in the study.

\section{MATERIALS AND METHODS}

\subsection{Field investigations}

\subsubsection{Site description}

Field investigations were conducted at the Runoff Monitoring Station of the University of Bologna (Ozzano Emilia, Italy; $\left.44^{\circ} 28^{\prime} \mathrm{N}, 11^{\circ} 28^{\prime} \mathrm{E}\right)$. The soil was classified as a loam (Udertic Ustochrepts, fine, mixed, mesic) with $42 \%$ sand, $34 \%$ silt, $24 \%$ clay, organic matter $1.6 \%$ and $\mathrm{pH}$ of 7.7 . The experimental site is described in detail in Miao et al. (2004). Briefly, the experimental site consisted of eight $350-\mathrm{m}^{2}$ plots $(7 \mathrm{~m}$ wide by $50 \mathrm{~m}$ long) with the longest side perpendicular to contour lines (Fig. 1). Field plots presented a uniform slope of $15 \%$ along their longest side. The plots were hydrologically isolated by means of ditches and separated by a $5 \mathrm{~m}$ wide by $50 \mathrm{~m}$ long buffer area. Runoff waters and sediments were collected in polyvinyl chloride (PVC) lined ditches located at the bottom of each field plot. Collected runoff water and sediment was transported by gravity to the field laboratory by means of aluminium pipes. Upon arriving at the field laboratory, the volume of collected runoff slurry was recorded continuously and runoff samples for herbicide analysis were collected using a pumping automated sampler. During sampling, runoff slurry was mechanically mixed. Collected samples were temporarily stored at $5^{\circ} \mathrm{C}$ for no longer than 24 hours. Once transported to the laboratory, samples were stored at $-20{ }^{\circ} \mathrm{C}$ until analysis.

During the whole 3-year period, rainfall and air temperature were recorded continuously by a weather station located approximately $100 \mathrm{~m}$ from the experimental area. The investigation was conducted under natural rainfall.

\subsubsection{Field plot management and herbicide treatments}

During the 3-year investigation period (2000-2002), the eight plots were cultivated with corn. Before each growth season, field plots were mouldboard-plowed to a depth of $25 \mathrm{~cm}$ at the end of September, followed by two secondary tillage passes for seedbed preparation. Field plots were managed following normal agricultural practices, which included phosphorus fertilization shortly before mouldboard plowing, and nitrogen fertilization at corn planting and 5-6 weeks after corn emergence. Corn (cv. Cecilia; Pioneer Hybrid Italia S.p.A., Italy) was planted at 6.8 seeds $\mathrm{m}^{-2}$. During the whole experimental period, the corn was harvested at the beginning of October.

Glyphosate and glufosinate-ammonium were applied shortly after seeding (mid-April), following a completely randomized block design, with four replicates. Both the herbicides were applied at the rate of $1.2 \mathrm{~kg}$ active ingredient (a.i.) ha ${ }^{-1}$. Glyphosate was applied as Roundup Bioflow ${ }^{\text {TM }}$ (isopropylamine salt of glyphosate, suspension concentrate, containing $360 \mathrm{~g}$ a.i. $\mathrm{L}^{-1}$ formulation; Monsanto Agricoltura Italia 
S.p.A., Lodi, Italy) and glufosinate-ammonium as Basta $^{\mathrm{TM}}$ (ammonium salt of glufosinate-ammonium, suspension concentrate, containing $120 \mathrm{~g}$ a.i. $\mathrm{L}^{-1}$ formulation; Bayer CropScience S.r.l., Milano, Italy). Although this is not the normal way of using glyphosate and glufosinate-ammonium in Italy, pre-emergence application of the two herbicides is, to some extent, consistent with their usage in glyphosate- or glufosinate-ammonium-tolerant corn. Weed control included a preemergence application of the selective herbicide metolachlor.

\subsection{Laboratory investigations}

Investigations into herbicide persistence and sorption in soil were carried out using surface (0-20-cm depth) soil samples collected at the above described experimental site a few days before starting the investigation. The soil had never received glyphosate or glufosinate-ammonium treatment. Soil was airdried and passed through a 2-mm sieve.

\subsubsection{Herbicide persistence}

For the herbicide persistence study, $5 \mathrm{~g}$ of soil (air-dried basis) were weighed in culture tubes and treated with glyphosate or glufosinate-ammonium water solutions, using the same commercial formulation adopted in the field investigation. Both the herbicides were applied at $10 \mu \mathrm{g}$ a.i. $\mathrm{g}^{-1}$ soil (air-dried basis). Soil moisture was adjusted to the field capacity $(-33 \mathrm{kPa})$ and samples were incubated in the dark in a climatic chamber at $25 \pm 0.5^{\circ} \mathrm{C}$. During the whole 21 -day incubation period, soil moisture was adjusted at 3-day intervals. At each sampling time $(0,1,7,14$ and 21 days) triplicate samples were removed and stored at $-20{ }^{\circ} \mathrm{C}$ until analysis. To estimate the role of abiotic processes on the degradation of glyphosate and glufosinateammonium in soil, the whole experiment was repeated using sterile soil. Soil was sterilized by autoclaving twice for $1 \mathrm{~h}$ at $121{ }^{\circ} \mathrm{C}$ and $103 \mathrm{kPa}$. Herbicide solutions were filter-sterilized and all the operations were done under a laminar flow hood.

Herbicide concentration data obtained from high performance liquid chromatography (HPLC) analysis were conventionally analyzed assuming the following first-order kinetics: $\ln C=\ln C_{0}-k t$, where $t$ is the sampling time in days, $C_{0}(100 \%)$ is the initial amount of pesticide, $C$ is a percentage of the initial amount remaining at time $t$, and $k$ is a rate constant in this equation. Parameters were obtained using linear regression. Regression analyses were performed using the software package Statitica ver. 6.1 (StatSoft Italia s.r.1., Milano, Italy, 1996). Formal F-tests for goodness of fit were performed by the analysis of variance of the obtained regression results. Herbicide half-life $\left(t_{1 / 2}\right)$ was calculated by the following equation: $t_{1 / 2}=$ $(\ln 2) / k$.

\subsubsection{Herbicide sorption isotherms}

Sorption isotherms of glyphosate and glufosinate-ammonium on soil were determined using the batch equilibrium method. Two grams (air-dried basis) of soil were weighed into 75-mL glass centrifuge tubes and $20 \mathrm{~mL}$ of herbicide solution prepared in $0.01 \mathrm{M} \mathrm{CaCl}_{2}$ was added. Similarly to the degradation study, glyphosate and glufosinate-ammonium were applied as Roundup Bioflow ${ }^{\mathrm{TM}}$ and Basta ${ }^{\mathrm{TM}}$, respectively. Sorption isotherms were determined using triplicate samples at five initial herbicide concentrations, ranging from 0.05 to $10 \mu \mathrm{g} \mathrm{mL}^{-1}$. Tubes were sealed with teflon-lined caps and shaken mechanically at $21 \pm 2{ }^{\circ} \mathrm{C}$. After 12 hours, samples were centrifuged at $3000 \mathrm{rpm}$ for $15 \mathrm{~min}$. Aliquots of the supernatant were filtered and analyzed for herbicide concentration. Amounts of sorbed glyphosate and glufosinate-ammonium were calculated from the concentration differences between the initial and equilibrium solution. Sorption data were fitted to the linear isotherm: $\mathrm{C}_{\mathrm{s}}=\mathrm{K}_{\mathrm{d}} \mathrm{C}_{\mathrm{e}}$, where $\mathrm{C}_{\mathrm{s}}$ is the concentration of sorbed herbicide ( $\mu \mathrm{g} \mathrm{g}^{-1}$ soil), $\mathrm{C}_{\mathrm{e}}$ is the herbicide equilibrium concentration and $\mathrm{K}_{\mathrm{d}}\left(\mathrm{mL} \mathrm{g}^{-1}\right)$ is the distribution coefficient. Preliminary investigations showed that 12 hours were sufficient to reach sorption equilibrium and that no significant degradation of glyphosate and glufosinate-ammonium occurred.

\subsection{Herbicide analysis}

Collected runoff samples were analyzed by HPLC following pre-column derivatization. Before analysis, aliquots of the runoff slurries were centrifuged (10 $000 \mathrm{rpm}$ for $20 \mathrm{~min}$ ) and the percent of sediments determined. The supernatant was filtered (0.70- $\mu \mathrm{m}$ size filter) and aliquots were extracted using an SPE anion exchange column. The pellet was extracted using a $0.1 \mathrm{M}$ potassium phosphate monobasic solution $(\mathrm{pH} 8)$. Water and sediment subsamples were analyzed for glyphosate, glufosinate-ammonium and aminomethylphosphonic acid (AMPA), the main metabolite of glyphosate, following the method described below and the total herbicide concentration of runoff slurry samples calculated.

Chemical analysis was performed according to the methodology proposed by Miles and Moye (1988). Derivatization was achieved by mixing to $0.1 \mathrm{~mL}$ of $0.2 \mu \mathrm{m}$ filtered sample, $0.9 \mathrm{~mL}$ borate buffer, $0.9 \mathrm{~mL}$ acetone and $0.1 \mathrm{~mL}$ of $0.01 \mathrm{M} 9$-fluorenylmethyl chloroformate in acetone. After $20 \mathrm{~min}$ of reaction at room temperature, the mixture was extracted with three $1-\mathrm{mL}$ washes of ethyl ether. Derivatized samples were analyzed by a chromatograph system that consisted of a Waters 501 pump (Waters Corp., St. Milford, MD), a Rheodyne 7125 injector (Rheodyne Europe $\mathrm{GmbH}$, Bensheim, Germany), a $0.46 \times$ $25 \mathrm{~cm}$ Luna $\mathrm{NH}_{2}$ column (Phenomenex Inc.), and a RF-10AXL spectrofluorometric detector (Shimadzu Italia S.r.l., Milano, Italy). The isocratic elution was carried out at room temperature and the eluent flow was set at $1.5 \mathrm{~mL} \mathrm{~min}^{-1}$ with acetonitrile/ $0.05 \mathrm{M}$ potassium phosphate monobasic ( $\mathrm{pH}$ 6.0) solution (35/ $65, \mathrm{v} / \mathrm{v})$. The detection of these three compounds was achieved by setting the detector at excitation and emission wavelengths of 285 and $370 \mathrm{~nm}$, respectively.

For the herbicide persistence experiment, soil samples treated with glyphosate and glufosinate-ammonium were extracted using a $0.1 \mathrm{M}$ potassium phosphate monobasic solution ( $\mathrm{pH}$ 8). Briefly, $250 \mathrm{~mL}$ of $0.1 \mathrm{M}$ potassium phosphate monobasic solution ( $\mathrm{pH} 8$ ) were added to the 5-g soil samples. Samples were shaken for 12 hours using an orbital shaker. After centrifugation at $3000 \mathrm{rpm}$ for $20 \mathrm{~min}$, supernatant aliquots were filtered through a $0.2-\mu \mathrm{m}$ size filter and analyzed.

All the employed reagents were analytical grade and supplied by Carlo Erba Reagenti S.p.A. (Milano, Italy). Herbicide standard solutions were prepared using analytical grade glyphosate (98\%), glufosinate-ammonium (94.5\%) and AMPA provided by Dr. Ehrenstorfer GmbH (Augsburg, Germany). 
Table I. Rainfall and runoff data recorded during the three corn-growing seasons.

\begin{tabular}{|c|c|c|c|c|c|}
\hline \multirow[t]{2}{*}{ Date } & \multirow[t]{2}{*}{ DAT $^{\mathrm{a}}$} & \multicolumn{2}{|c|}{ Rainfall Events } & \multirow{2}{*}{$\begin{array}{c}\text { Runoff } \\
\text { Events } \\
(\mathrm{mm})\end{array}$} & \multirow{2}{*}{$\begin{array}{c}\text { Outflow Coefficient } \\
\text { (\%) }\end{array}$} \\
\hline & & Amount (mm) & Max. Intensity ${ }^{\mathrm{b}}\left(\mathrm{mm} \mathrm{h}^{-1}\right)$ & & \\
\hline $15 / 07 / 00$ & 86 & 19.8 & 18 & $0.05 \pm 0.03$ & 0.27 \\
\hline 28/07/00 & 99 & 26.2 & 78 & $0.22 \pm 0.03$ & 0.82 \\
\hline 05/09/00 & 107 & 58.6 & 46 & $0.32 \pm 0.03$ & 0.55 \\
\hline 07/10/00 & 170 & 39.8 & 25 & $0.12 \pm 0.06$ & 0.30 \\
\hline $11 / 04 / 01$ & 1 & 35.4 & 16 & $0.08 \pm 0.03$ & 0.22 \\
\hline 06/05/01 & 26 & 8.6 & 19 & $0.32 \pm 0.05$ & 3.74 \\
\hline 07/05/01 & 27 & 2.4 & 4 & $0.26 \pm 0.05$ & 10.92 \\
\hline $21 / 05 / 01$ & 41 & 17.8 & 16 & $0.27 \pm 0.05$ & 1.53 \\
\hline $15 / 07 / 02$ & 77 & 44.2 & 43 & $0.68 \pm 0.19$ & 1.53 \\
\hline $18 / 07 / 02$ & 80 & 30.6 & 63 & $0.66 \pm 0.29$ & 2.16 \\
\hline $24 / 07 / 02$ & 86 & 11.4 & 10 & $1.01 \pm 0.22$ & 8.83 \\
\hline 23/08/02 & 116 & 29.0 & 83 & $0.23 \pm 0.07$ & 0.79 \\
\hline $29 / 08 / 02$ & 122 & 31.4 & 53 & $0.31 \pm 0.03$ & 0.99 \\
\hline 01/09/02 & 125 & 10.0 & 48 & $0.29 \pm 0.1$ & 2.90 \\
\hline 06/09/02 & 130 & 14.8 & 24 & $0.12 \pm 0.08$ & 0.78 \\
\hline $11 / 09 / 02$ & 135 & 17.0 & 18 & $0.22 \pm 0.12$ & 1.29 \\
\hline $23 / 09 / 02$ & 147 & 92.6 & 28 & $0.40 \pm 0.15$ & 0.43 \\
\hline 06/10/02 & 160 & 17.2 & 11 & $0.80 \pm 0.14$ & 4.75 \\
\hline
\end{tabular}

${ }^{\mathrm{a}}$ Days after treatment.

${ }^{\mathrm{b}}$ Maximum 30-minute rainfall intensity.

${ }^{\mathrm{c}}$ Percentage of the total incident rainfall recovered as surface runoff.

\section{RESULTS AND DISCUSSION}

\subsection{Rainfall and runoff events}

During 2000 and 2001, annual rainfall was 16 and $31 \%$ below the 10-year average of the experimental site $(740 \mathrm{~mm})$, respectively. In contrast, during 2002, annual rainfall was $32 \%$ above the 10-year average value. In the whole experimental period, rain intensity ranged from 4 to $83 \mathrm{~mm} \mathrm{~h}^{-1}$. As observed in previous investigations (Vicari et al., 1999; Miao et al., 2004), the highest intensity values were observed during the corn growth season (April-September), and more frequently at the end of summer (Tab. I).

Runoff events and runoff volumes observed during the experimental period are reported in Table I and Figure 2. The adopted $350-\mathrm{m}^{2}$ field plots permitted the satisfactory control of spatial variability of runoff processes (Screpanti, 2005). Consequently, runoff data are presented as average values of the 8 plots.

During the first growing season (April-October 2000) only $0.5 \%$ of the cumulated rainfall causing runoff was recovered as runoff. In the remaining crop-growing seasons, recoveries were approximately 2.5 times higher than in 2000 (Tab. I). Differences in outflow coefficient (ratio between runoff volume and total rain generating the runoff event) values have been reported in the experimental site (Rossi Pisa et al., 1999). Obviously, apart from precipitation characteristics (i.e. precipitation intensity and duration), occurrence and intensity of runoff events largely depend on soil moisture level, crop growth stage and other uncontrolled factors (Wauchope et al., 2001). In the present research, measured runoff volumes were lower than the 10 -year average of the experimental site $\left(10.4 \mathrm{~mm}\right.$ year $\left.^{-1}\right)$. Dramatic differences in time occurrence, patterns and intensity of rainfall events are frequently observed in the Mediterranean area (Ventura et al., 2002).

\subsection{Herbicide concentrations and losses in runoff water}

Concentrations of glyphosate and glufosinate-ammonium in collected runoff samples are shown in Figure 2. As expected, herbicide concentrations rapidly declined with time. This tendency is largely reported in the literature (Wauchope, 1978; Edwards et al., 1980; Leonard, 1989; Shipitalo et al., 1997; Shipitalo and Malone, 2000). In the present experiment, because of the measured short persistence of the two herbicides (Tab. II) and the high air temperatures observed during the growing season (data not shown), the phenomenon was markedly pronounced. In addition, according to Koskinen et al. (2003), herbicide availability to water transport decreases with increasing contact time with soil particles.

In 2000 and 2002, the first runoff events were observed approximately 2 months after herbicide treatments. Consequently, low herbicide concentration values were measured during these two years. More precisely, during the two years, glyphosate and glufosinate-ammonium concentrations did not 


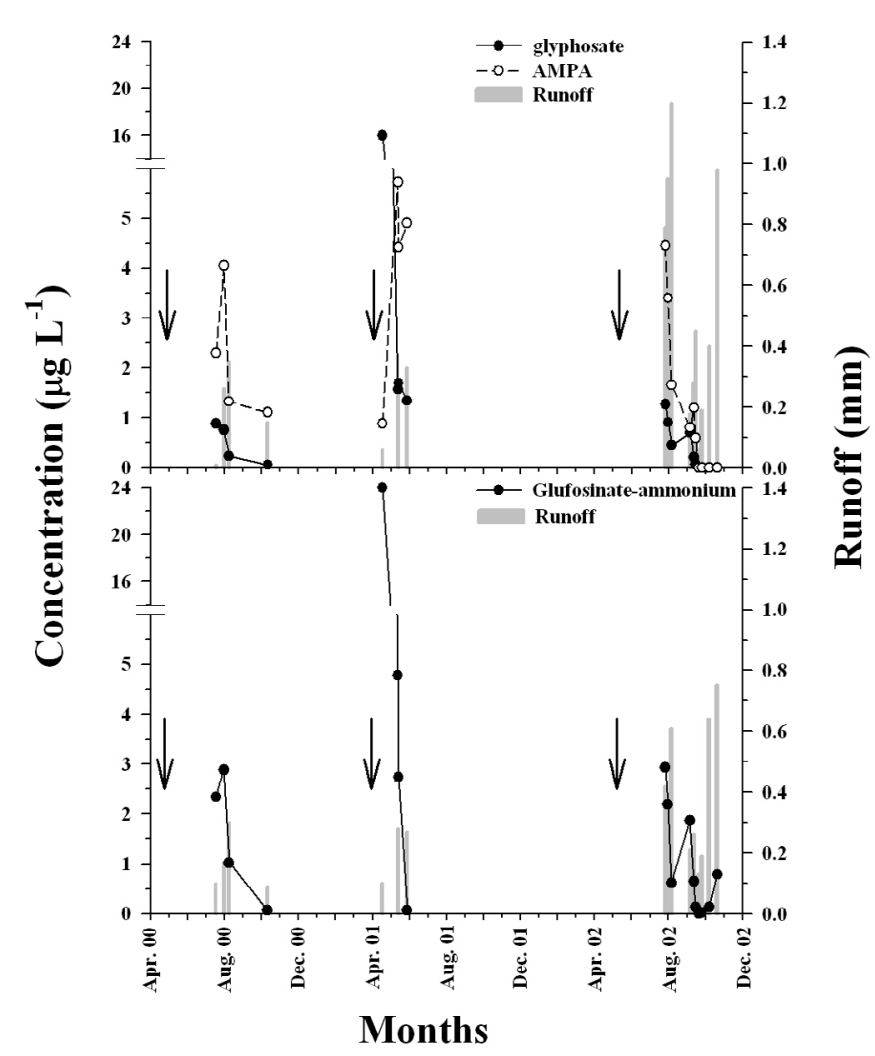

Figure 2. Runoff events and concentrations of glyphosate, aminomethylphosphonic acid (AMPA) and glufosinate-ammonium in runoff samples during the three corn-growing seasons. Arrows indicate timing of herbicide applications.

exceed 1.5 and $3.0 \mu \mathrm{g} \mathrm{L}^{-1}$, respectively. In contrast to 2000 and 2002, in 2001 the first runoff event occurred 1 day after treatment. The highest herbicide concentrations were observed in coincidence with this runoff event. During 2002, glyphosate and glufosinate-ammonium concentration peaks were approximately 10 and 4 times higher than those of the other two years, respectively (Fig. 2). In the whole experimental period, glufosinate-ammonium showed higher concentration values with respect to glyphosate, thus confirming its relatively higher mobility in soil. Concentration values of aminomethylphosphonic acid (AMPA), the main metabolite of glyphosate, are reported in Figure 2. The observed values of AMPA concentration in runoff samples supported the rapid degradation of the parent compound in soil. Despite its shorter persistence in soil, as determined in the laboratory experiment, in 2002 glufosinate-ammonium was detected approximately five months after treatment.

Because of the low values of runoff volumes and herbicide concentrations, low losses of the two herbicides were estimated. Maximum glyphosate and glufosinate-ammonium losses were observed in 2001 and accounted for only 0.031 and $0.064 \%$ of the total applied amount, respectively (Fig. 3). On the basis of the estimated herbicide losses, the present investigation reinforced the low potential of glyphosate and glufosinate-ammonium to contaminate surface waters. However,
Table II. Half-life $\left(t_{1 / 2}\right)$ and distribution coefficient $\left(\mathrm{K}_{\mathrm{d}}\right)$ values of glyphosate and glufosinate-ammonium in the Ozzano soil.

\begin{tabular}{|c|c|c|c|c|}
\hline \multirow[t]{2}{*}{ Herbicide } & \multicolumn{2}{|c|}{ Half-life } & \multicolumn{2}{|c|}{$\begin{array}{c}\text { Distribution } \\
\text { Coefficient }\end{array}$} \\
\hline & $\mathrm{t}_{1 / 2}$ (days) & $r^{2}$ & $\mathrm{~K}_{\mathrm{d}}\left(\mathrm{mL} \mathrm{g}^{-1}\right)$ & $r^{2}$ \\
\hline Glyphosatephosate & $17.5 \pm 0.7^{\mathrm{a}}$ & $0.90^{\mathrm{b}}$ & 746.6 & 0.97 \\
\hline Glufosinate-ammonium & $6.4 \pm 0.1$ & 0.99 & 23.4 & 0.95 \\
\hline
\end{tabular}

${ }^{\text {a }}$ Standard error of the mean.

${ }^{\mathrm{b}}$ Coefficient of determination.

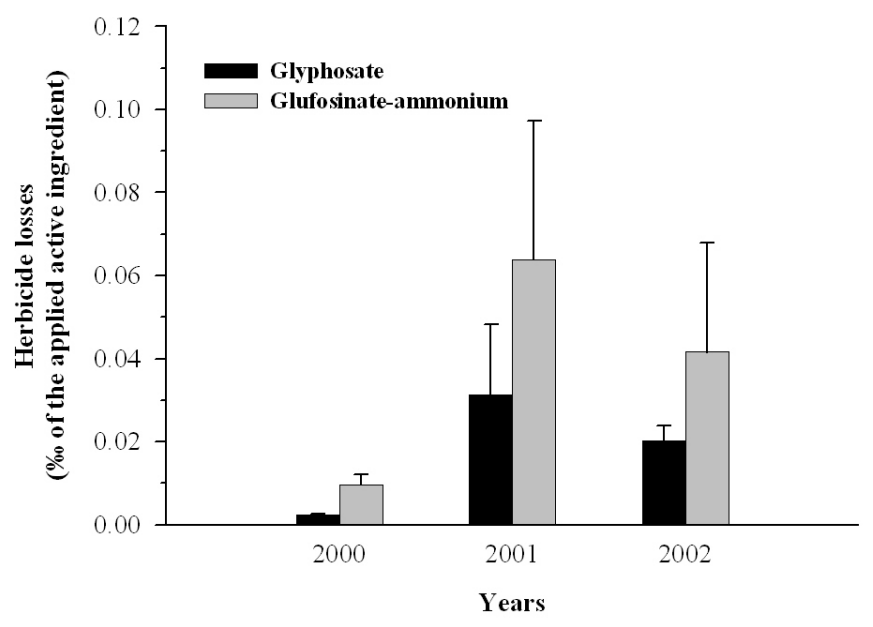

Figure 3. Surface runoff losses of glyphosate and glufosinate-ammonium during the three corn-growing seasons. Vertical bars are standard errors of the mean.

considering the herbicide concentrations, both herbicides may significantly contaminate surface waters only when high intensity rainfall occurs shortly after herbicide application. Even though the two herbicides are strongly sorbed on soil, significant contamination of surface waters should not be excluded. The important role of the timing of runoff event occurrence is largely reported in the literature (Wauchope, 1978; Burgoa and Wauchope, 1995; Shipitalo et al., 1997). Thus the present investigation confirmed the importance of this phenomenon in the overall losses of herbicides.

\subsection{Herbicide persistence and sorption}

The half-lives of glyphosate and glufosinate-ammonium in soil are reported in Table II. For both herbicides, degradation was correctly described by the first-order kinetic model as indicated by the coefficient of determination. The half-lives of glyphosate and glufosinate-ammonium were 17.5 and 6.4 days, respectively (Tab. II). These findings are in agreement with those obtained in a previous study conducted with soil from the same experimental site (Accinelli et al., 2004).

Negligible degradation of both glyphosate and glufosinateammonium was observed in sterile soil (data not shown), thus 
confirming that degradation of glyphosate and glufosinateammonium is a microbial process (Torstensson, 1985; Accinelli et al., 2004).

Sorption of glyphosate and glufosinate-ammonium on soil over the adopted herbicide concentrations was correctly described by linear isotherms (Tab. II). Linear sorption isotherms of glyphosate and glufosinate-ammonium on soil have been reported by other authors (Gallina and Stephenson, 1992; Gerritse et al., 1996). The estimated distribution coefficients of glyphosate and glufosinate-ammonium were 746.6 and $23.4 \mathrm{~mL} \mathrm{~g}^{-1}$, respectively. Although glufosinate-ammonium sorption was significantly lower than that of glyphosate, both the herbicides showed limited potential for transport. Despite its low potential mobility, glyphosate transport in soil higher than that predicted on the basis of its physico-chemical properties has been reported (de Jonge et al., 2000).

Data obtained in the laboratory supported the low glyphosate and glufosinate-ammonium losses observed in the field investigation. In general, both herbicides present low potential to contaminate surface waters, as predicted by their rapid degradation and strong sorption in soil. Estimated herbicide losses and concentrations were markedly lower with respect to other herbicides (i.e. atrazine, metolachlor and terbuthylazine) tested in previous years in the same experimental station. According to Wauchope et al. (2001), glyphosate and glufosinate-ammonium are characterized by a lower potential to contaminate surface water bodies with respect to a wide range of residual herbicides, including atrazine and metolachlor.

\section{CONCLUSIONS}

The adopted automated runoff monitoring system permitted an accurate estimation of glyphosate and glufosinate-ammonium losses. In the present 3-year investigation, because of moderate runoff volumes, low herbicide losses were observed. On the basis of the obtained results, both glyphosate and glufosinate-ammonium showed low potential to contaminate surface waters. The timing of rainfall relative to the application date was confirmed as an important factor influencing herbicide losses, even for strongly sorbed herbicides such as glyphosate and glufosinate-ammonium. These findings suggested that herbicide contamination of surface waters cannot be correctly predicted on the sole basis of the physico-chemical properties of herbicides.

Acknowledgments: The authors wish to thank Syngenta Ltd. (Basel, Switzerland) for financial support. Special thanks are given to Dr. F. Ventura and Dr. N. Gaspari for scientific assistance.

\section{REFERENCES}

Accinelli C., Screpanti C., Vicari A., Catizone P. (2004) Influence of insecticidal toxins from Bacillus thuringiensis subsp. kurstaki on degradation of glyphosate and glufosinate-ammonium in soil samples, Agric. Ecosyst. Environ. 103, 497-507.

Burgoa B., Wauchope R.D. (1995) Pesticides in runoff and surface waters, in: Roberts R., Kennedy P.C. (Eds.), Environmental behaviour of agrochemicals, John Wiley \& Sons Ltd, NY, pp. 221-255.
Carter A.D. (2000) Herbicide movement in soils: principles, pathways and processes, Weed Res. 40, 113-122.

de Jonge H., de Jonge L.W., Jacobsen O.H. (2000) [ $\left.{ }^{14} \mathrm{C}\right]$ Glyphosate transport in undisturbed topsoil columns, Pest Manag. Sci. 56, 909-915.

Edwards W.M., Triplett W.B., Kramer R.M. (1980) A watershed study of glyphosate transport in runoff, J. Environ. Qual. 9, 661-665.

Gallina M.A., Stephenson G.R. (1992) Dissipation of [14C]glufosinateammonium in two Ontario soils, J. Agric. Food Chem. 40, 165-168.

Gaynor J.D., Tan C.S., Drury C.F., Ng H.Y.F., Welacky T.W., Wesenbeeck I.J. (2001) Tillage, intercrop, and controlled drainage-subirrigation influence atrazine, metribuzin, and metolachlor loss, J. Environ. Qual. 30, 561-572.

Gerritse R.G., Beltran J., Hernandez F. (1996) Adsorption of atrazine, simazine and glyphosate to soil materials of the Gnangara Mound in Western Australian, Aust. J. Soil Res. 34, 599-607.

Giesy J.P., Dobson S., Solomon K.R. (2000) Ecotoxicological risk assessment for Roundup ${ }^{\mathrm{TM}}$ herbicide, Rev. Environ. Contam. Toxicol. 167, 35-120.

Koskinen W.C., Anhalt J.A., Sakaliene O., Rice P.J., Moorman T.B., Arthur E.L. (2003) Sorption-desorption of two "aged" sulfonylaminocarbonyltriazolinone herbicide metabolites in soil, J. Agric. Food Chem. 51, 3604-3608.

Leonard R.A. (1989) Herbicides in surface waters, in: Grover G. (Ed.), Environmental chemistry of herbicides, CRC Press, Boca Raton, FL., pp. 46-87.

Miao Z., Vicari A., Capri E., Ventura F., Padovani L., Trevisan M. (2004) Modeling the effects of tillage management practices on herbicide runoff in Northern Italy, J. Environ. Qual. 33, 1720-1732.

Miles C.J., Moye H.A. (1988) Extraction of glyphosate herbicide from soil and clay minerals and determination of residues in soils, J. Agric. Food Chem. 36, 486-491.

Parr B.A., Zou S., McEnroe B. (1998) Effects of infiltration on agricultural runoff contamination, J. Environ. Eng.-ASCE 124, 863-868.

Rossi Pisa P., Preti F., Rossi M., Ventura F., Mazzanti B. (1999) Water, soil and chemical losses: field experiments and model analysis, Water Sci. Tech. 39, 93-102.

Screpanti C. (2005) Field and laboratory investigations on glyphosate and glufosinate-ammonium runoff, Ph.D. Thesis, Department of AgroEnvironmental Science and Technology, University of Bologna, Italy.

Shaner D.L. (2000) The impact of glyphosate-tolerant crops on the use of other herbicides and on resistence management, Pest Manag. Sci. 56, 320-326.

Shipitalo M., Edwards W.M., Owens L.B. (1997) Herbicides losses in runoff from conservation-tilled watersheds in a corn-soybean rotation, Soil Sci. Soc. Am. J. 61, 267-272.

Shipitalo M.J., Malone R.W. (2000) Runoff losses of pre and post-emergence herbicides from watersheds in a corn-soybean rotation, Ohio Agricultural Research and Development Center, University of Ohio, OH, pp. 1-4.

Torstensson L. (1985) Behaviour of glyphosate in soils and its degradation, in: Grossbard E., Atkinson E. (Eds.), The herbicide glyphosatephosate, Butterworths, London, pp. 137-149.

Ventura F., Rossi Pisa P., Ardizzoni E. (2002) Temperature and precipitation trends in Bologna (Italy) from 1952 to 1999, Atmos. Res. 61, 203-214.

Vicari A., Rossi Pisa P., Catizone P. (1999) Tillage effects on runoff losses of atrazine, metolachlor, prosulfuron and triasulfuron, Abstract of the 11th EWRS Symposium, Basel, Switzerland, p. 140.

Wauchope R.D. (1978) The pesticide content of surface water draining from agricultural field, a review, J. Environ. Qual. 7, 459-472.

Wauchope R.D., Estes T.L., Allen R., Baker L.J., Hornsby A.G., Jones R.L., Richards R.P., Gustafson D.I. (2001) Predicted impact of transgenic, herbicide-tolerant corn on drinking water quality in vulnerable watersheds of the mid-western USA, Pest Manag. Sci. 58, 146-160.

Zaranyika M.F., Nyandoro M.G. (1993) Degradation of glyphosate in the aquatic environment: an enzymatic kinetic model that takes into account microbial degradation of both free and colloidal (or sediment) particle adsorbed glyphosate, J. Agric. Food Chem. 41, 838842 . 